$$
\begin{gathered}
\text { 다중 빔 음향측심 자료의 } \mathrm{CUBE} \text { 필터링 } \\
\text { 김주연·이광수 }{ }^{*} \cdot \text { 김 대철 }^{1} \text { 서 영 교 }{ }^{2} \text { 이희 일 }{ }^{3} \\
\text { (주) 오션테크, }{ }^{1} \text { 부경대학교 에너지자원공학과, }{ }^{2} \text { 지마텍(주), }{ }^{3} \text { 한국해양연구원 }
\end{gathered}
$$

\title{
CUBE Filtering of Multibeam Echo Sounder Data
}

\author{
Joo Youn Kim, Gwang Soo Lee ${ }^{1 *}$, Dae Choul Kim', \\ Young $\mathrm{Kyo} \mathrm{Seo}^{2}$ and $\mathrm{Hi}$ Il $\mathrm{Yi}^{3}$ \\ Oceantech Corporation, Seoul 157-846, Korea \\ ${ }^{1}$ Department of Energy Resources Engineering, Pukyong National University, \\ Busan 608-737, Korea \\ ${ }^{2}$ Gematek Corporation, Busan 608-020, Korea \\ ${ }^{3}$ Department of Marine Environment Research, Korea Ocean Research \& \\ Development Institute, Ansan 426-744, Korea
}

A MBES (multibeam echo sounder) survey around Yokji Island, Korea, was conducted to find an effective method for removing error data. Two post-processing software programs, PDS2000 (RESON) and HIPS (CARIS), were used to remove the error data using an interactive editing method and the CUBE algorithm filter. The post-processing with the PDS2000 and HIPS programs, using the interactive editing method, took 120 and 168 hours, respectively, and there was little difference in the seafloor images. The processing time of the PDS2000 and HIPS programs using the CUBE algorithm filter was 36 and 60 hours, respectively. Nevertheless, there was little difference in the seafloor images because of differences in the factor parameters in each of the post-processing programs. Therefore, post-processing using CUBE filtering can save time in data processing and provide consistent results, excluding the subjective decisions of the operator. This method is more effective than other methods for rejecting erroneous multibeam echo sounder data.

Key words: Multibeam echo sounder, Error data, CUBE filtering, Postprocessing

\section{서 론}

다중 빔 음향측심 시스템 (multibeam echo sounder system, $\mathrm{MBES})$ 은 음원을 기준으로 100 개 이상의 빔을 생성하여 해저 지형을 조사하는 장비로 오늘날 트랜스듀서와 부가 관측 장비 의 발달과 더불어 활발하게 사용되고 있다. 그러나 다중 빔 음향측심기의 부가 관측 장비는 수심자료의 처리성과를 높이 기도 하지만 기기의 오정렬과 오작동으로 인한 오측 자료를 생성하는 문제점도 있다. 다중 빔 음향측심기 운영 시 발생하 는 오차에는 시각 지연 오차, 헤딩 오차, 롤 관측오차, 피치 관측오차, 음속도 관측오차 등이 있으며 (Smith, 1991; Wells et al., 1991; Godin, 1996; Orange et al., 1999; Susan and Wells, 2000; Park, 2004; Kim, 2005; Alan, 2007), 해저지형조사를 위한 다중 빔 음향측심기의 활용도가 증가함과 동시에 오측 자료의 최소화를 위하여 오차요인을 분석하고 제거를 위한 연구가 전 세계적으로 진행되고 있다 (Hammack et al., 1998; Hare, 2001; Park, 2004; Kim, 2005; Christian de Moustier, 2008). 현장에서 발생하는 이러한 오차요인들은 일차적으로 다중 빔 음향측심기와 부가 관측 장비의 운영방식을 이해하고 각 장비들의 정확한 오프셋설정 및 올바른 사용으로 일정부분 제거가 가능하다 (Hammack et al., 1998; Park, 2004; Kim, 2005). 하지만 이와 같은 과정으로도 제거되지 않은 오측 자료

\footnotetext{
*Corresponding author: coolks@pknu.ac.kr
}

\section{는 후처리 프로그램을 이용해야만 한다.}

오늘날 후처리 프로그램을 이용한 오측 자료의 처리는 개개 의 핑별로 오측 자료를 제거하는 핑별 오측 자료 제거 방법 (interactive editing)이 주로 사용되고 있으며, 이 방법이 가장 정확한 해저면을 구현할 수 있는 방법임에는 분명하다. 하지 만 다중 빔 음향측심기의 특성상 한번의 조사에도 방대한 양의 측량자료가 축적됨으로 이를 개개의 핑별로 오측 자료를 처리하기에는 너무 많은 시간이 소요된다. 또한 오측 자료의 판별 기준은 전적으로 자료 처리자의 주관적 판단에 근거하므 로, 오측 자료 제거 기준이 일관적이지 않을 수 있으며, 잘못된 판단으로 인해 2차 오류가 발생하기도 한다 (CARIS, 2007). 이와 같은 후처리 과정 시 발생하는 문제를 보완하고 해결하 기 위해서는 해저 지형의 변화에 따른 상용프로그램의 자동화 처리기법과 핑별 오측 자료 제거 방법을 적절히 이용하여 객관적으로 해결하려는 연구가 요구된다. 또한 상용프로그램 의 자동화 처리기법을 이용했을 경우 기존 처리기법과 비교하 여 해저면 구현 정도와 처리에 소요된 시간 등에서 나타나는 차이를 정량적으로 비교해 볼 필요가 있다. 현재 가장 강력한 멀티 빔 자료제거방법 중 하나인 CUBE (combined uncertainty and bathymetry estimator) 알고리즘 필터링은 빔의 연속성에 의거하여 동화 (assimilation), 중재 (intervention), 확정 (disambiguation)의 과정에 따라 여러 개의 가상 해저면 (hypothesis)을 형성하고 이를 기준으로 자료의 변화 양상에 
따라 오측 여부를 판별하여 제거한다. 따라서 처리자의 주관 적인 판단을 배제하면서 자료처리를 위한 시간을 단축시킬 수 있는 이점을 가지고 있다 (Calder and Mayer, 2001; Calder, 2003; Mallace and Gee, 2004; Calder and Wells, 2007).

따라서 본 연구에서는 다중 빔 음향측심기 탐사 시 발생하 는 오차요인을 최소화하고, 자료처리의 객관성을 높이기 위하 여 후처리 프로그램내의 CUBE 알고리즘 필터링을 이용한 일관적인 자료처리 방법을 검토하고 제안하는데 그 목적이 있다. 또한 조사해역의 지형변화 정도와 오측 자료의 분포에 따라 필터링 요소의 효과를 비교하고 분석하여 그 효과의 효율성을 규명하고자 한다.

\section{재료 및 방법}

\section{조사해역의 특성}

연구해역인 통영시 욕지면 모도 해역은 한반도의 남쪽에 위치하며 욕지도와 노대도, 연하도에 둘러싸여 있다 (Fig. 1). 탐사해역은 모도에 근접해 있으며, 수심은 3-70 $\mathrm{m}$ 의 다양한 분포를 보이는 가운데 모도를 중심으로 남동쪽부근에 높이가 약 $30 \mathrm{~m}$ 의 급격한 수심의 변화를 보이는 지형이 존재한다. 이 주변으로 수심 $30 \mathrm{~m}$ 의 평탄한 해저지형이 나타나며 다수의 상자형 어초가 분포하고 있다. 욕지도 방향의 남쪽으로 갈수 록 수심이 급격히 깊어지면서 60-70 m의 깊은 수심대를 형성 하고 있다 (KIER, 1986, 1987; Min, 1994).

연구해역의 창조류는 욕지도와 연하도 사이를 통과할 때는 북서쪽에서 내만으로 유입되어 일부는 욕지 수도를 경유해 외해의 흐름과 합류하여 서쪽으로 이동한다 (Fig. 2). 낙조류는 이와 반대의 흐름을 보인다. 최강유속은 평균대조기에 창조류 는 0.5-1.3 Knot의 속도를 가지며, 낙조류는 0.7-1.8 Knot의 속 도로 낙조류가 조금 더 우세하다 (Jung, 2008; KHOA, 2008).

이처럼 연구해역의 환경은 조류의 영향력이 약하고 지형의 변화가 뚜렷이 구분될 뿐 아니라 일부해역에는 인공 구조물이
존재하기도 하여 본 연구 목적인 필터링 효과의 효율성을 연구하기에는 최적의 장소이다.

$$
\text { 자료획득 및 처리 }
$$

자료획득

본 연구를 위하여 SEABAT 7125 다중 빔 음향측심기 (RESON, Denmark)와 각 부가 관측 장비인 모션센서 (OCTAN, IXSEA, France), DGPS (Vector sensor, CSI, Canada), SVP (SVP-25, RESON, Denmark)를 사용하여 자료를 획득하였다. 모도에서 동서방향으로 $15 \mathrm{~km}$ 의 총 10 개의 조사측선과 정밀도 향상을 위하여 3 개의 검측선을 설계하여 수심자료를 획득하였 다 (Fig. 3). 조사 대상 해역에서 수심이 급격히 변하고 인공구조 물이 존재하는 곳은 정밀도를 향상시키기 위해 $80-100 \%$ 의 중첩 율을 가지도록 측선을 설계하였으며, 수심이 깊고 평탄한 해역 에서는 $10-20 \%$ 의 중첩율로 자료를 획득하였다.

각 부가 관측 장비는 그 특성을 고려하여 조사선 내에 임의 의 원점 (RP, reference point)에서 정확하게 측정된 값에 따라 최적의 위치에 장착하였다 (Fig. 4). 선박에 설정 한 원점과 해수면을 기준으로 측정된 각각의 부가 관측 장비 오프셋은 PDS2000 (RESON) 프로그램에 입력하여 다중 빔 음향측심 자료 획득 시 선박의 거동을 정확하게 측정하고 실시간으로 보정되도록 하였다. 자료 획득 시 총 4 개의 정점에서 다른 시간대에 SVP-25를 이용하여 수심에 따른 속도 변화를 측정 하여 후처리에 이용하였다.

\section{후처리 프로그램을 이용한 자료처리}

현장에서 획득 된 다중 빔 자료에는 음속도 오차, 롤 관측오 차, 피치 오차, 헤딩 오차, 조위 오차 등 다양한 오차 요인이 발생 한다 (Godin et al., 1996; Hughes Clark, 1997; Susan and Wells, 2000; Park, 2004; Alan, 2007). 따라서 정확한 자료 처리 를 위해 각 부가 관측 장비의 오프셋 설정 값, 모션센서에서

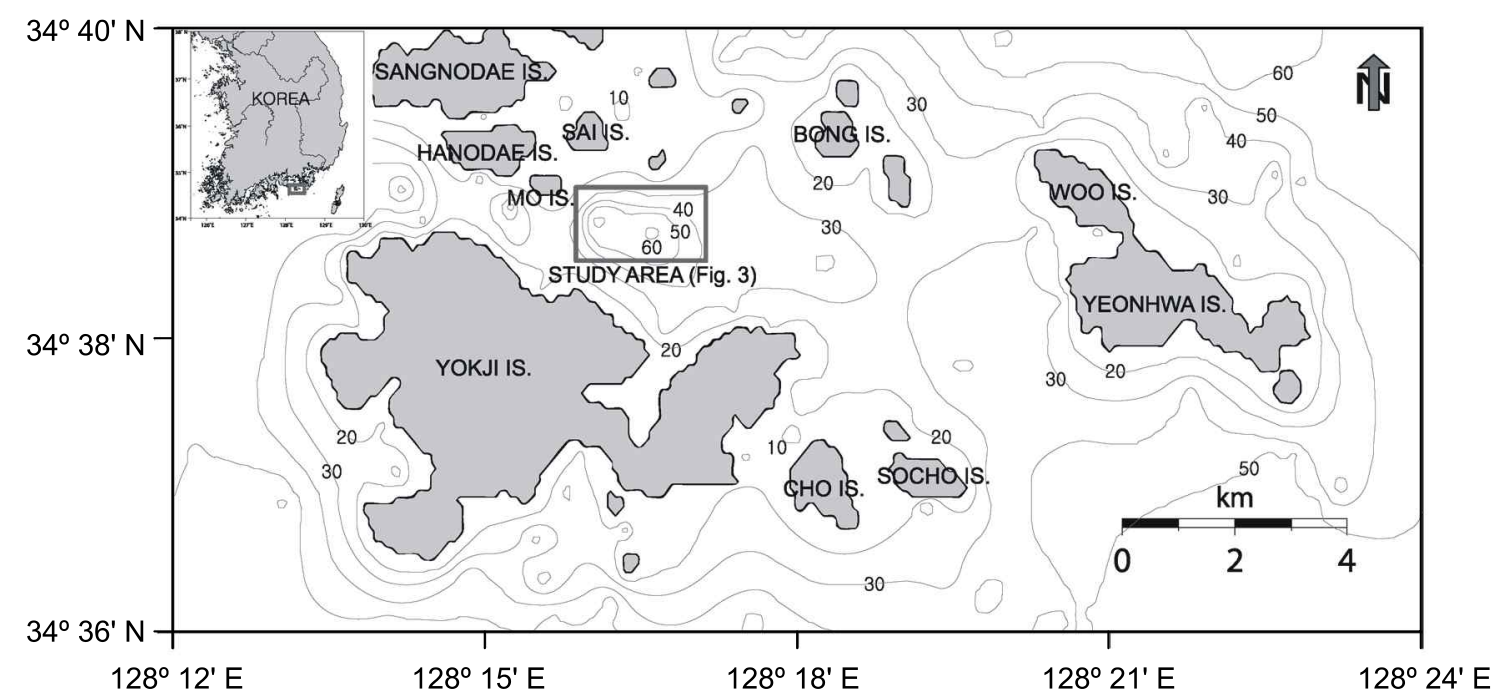

Fig. 1. The map of the study area. The study area index is marked by a box. Contours in meters. 

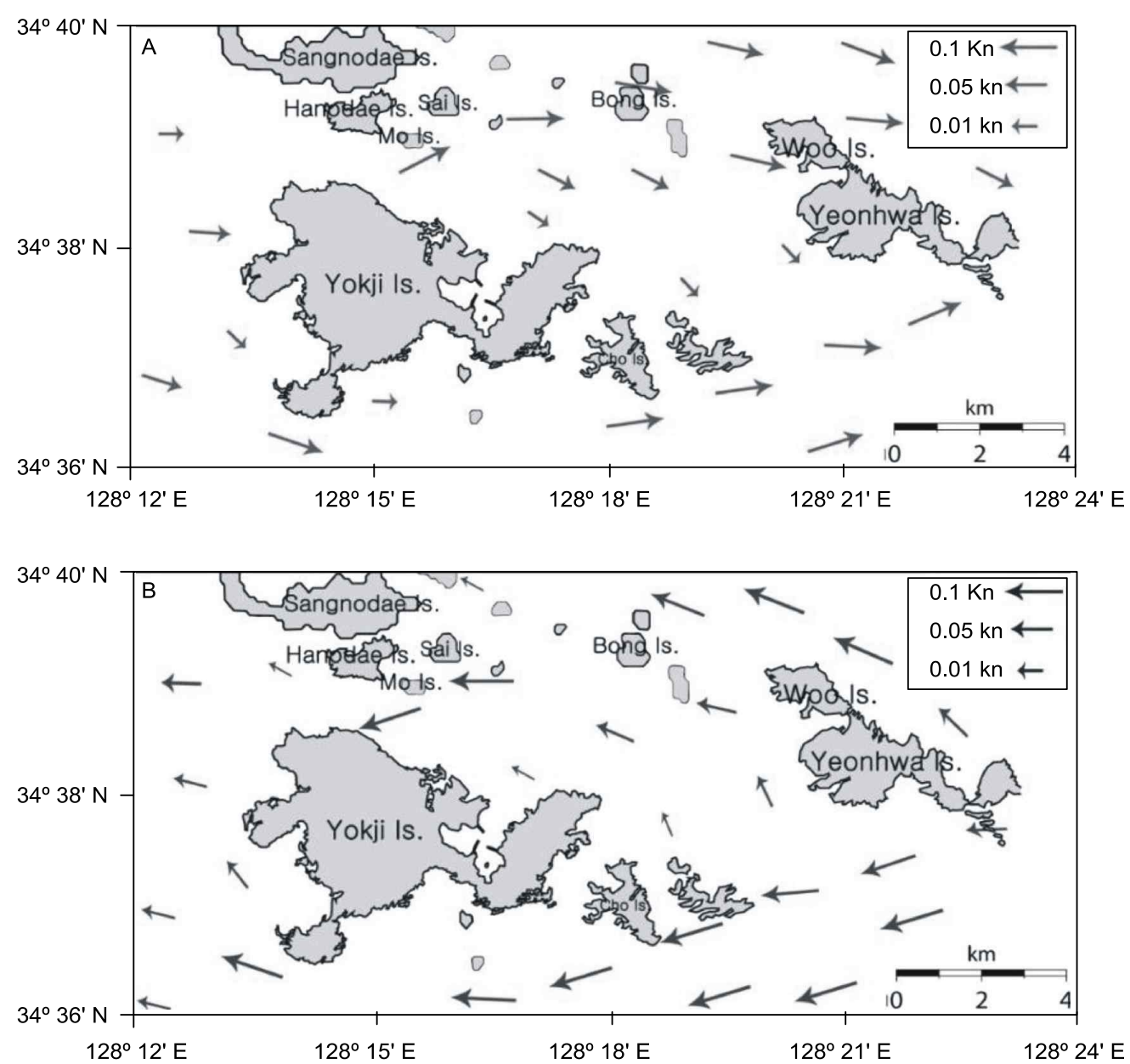

Fig. 2. Tidal current patterns and the maximum velocity during flood (A) and ebb (B) around Yokji Island. (Modified from the National Oceanographic Research Institute, 2008).

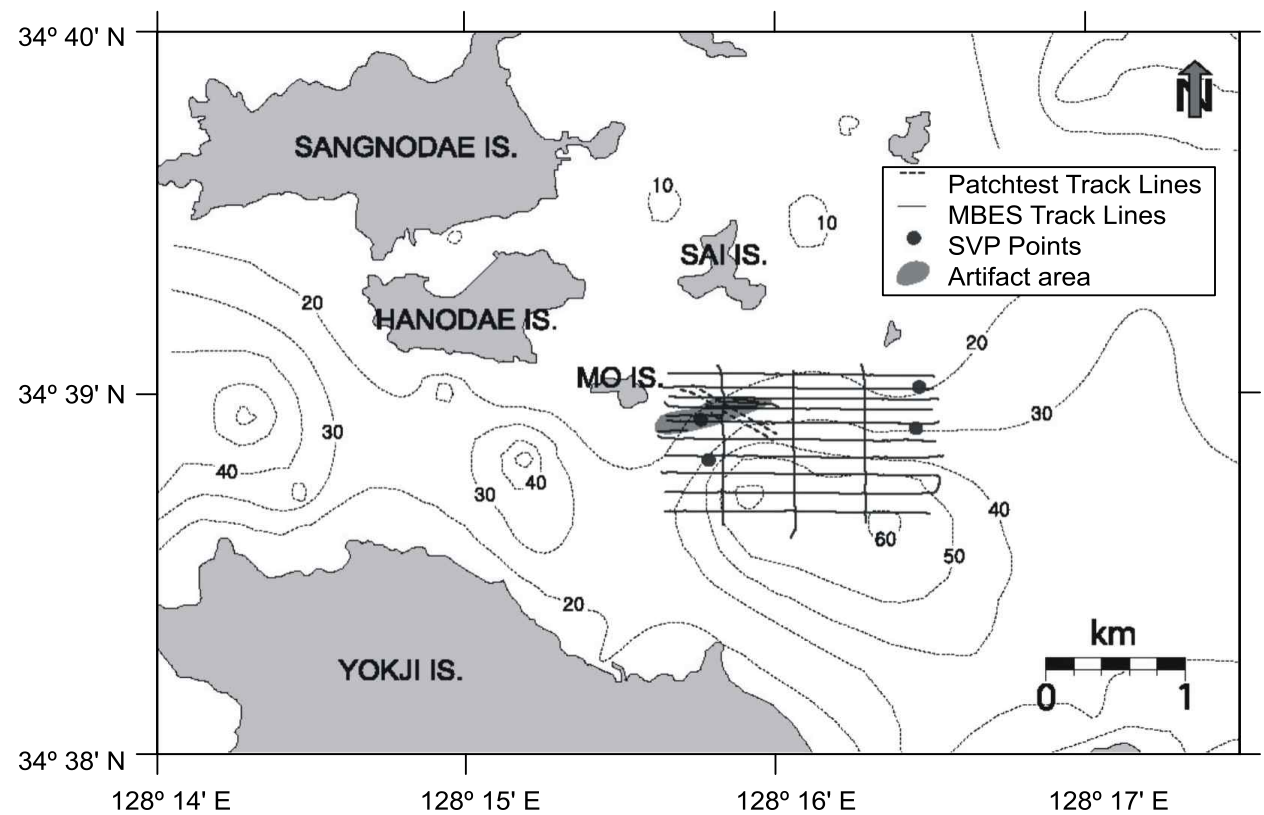

Fig. 3. Map of MBES survey track lines and SVP (sound velocity profiler) positions in the study area. Contours in meters. 


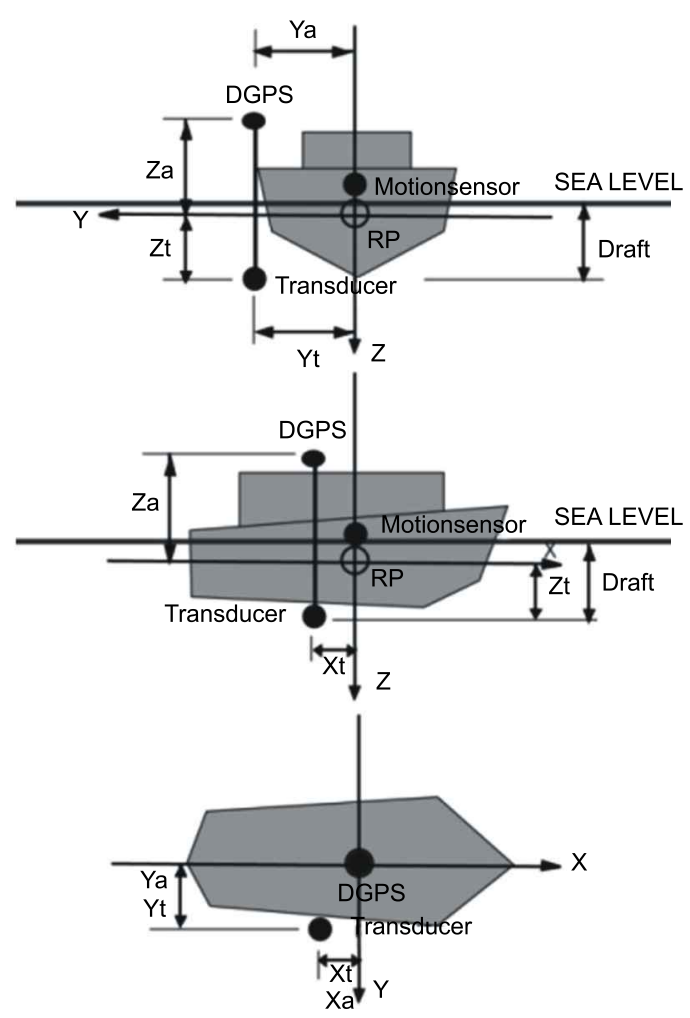

Fig. 4. Overview of MBES offsets in study vessel (Land information New Zealand, 2000).

획득된 보정 값, 수심에 따른 음속 측정 값, 조위 관측 자료 등을 이용하여 오프셋 보정, 음속도 보정, 롤 보정, 피치 보정, 헤딩 보정, 조위 보정 등을 자료 처리에 앞서 수행하였다. 또한, 소나 진동자 (sonar head)의 방향성을 정확하게 파악하고 보정하기 위하여 자료획득 시 패치테스트 (patchtest)를 실시하 여 (Fig. 3) 얻은 결과를 자료 처리과정에 적용하였다 (Herlihy et al., 1989; Hillard and Rulon, 1989; Hughes Clark., 1997; NOAA, 2004; Hughes Clark, 2007). 획득된 측심자료와 보정 자료는 PDS2000과 HIPS (CARIS)프로그램에서 핑별 오측 자 료 제거 기법과 $\mathrm{CUBE}$ 알고리즘을 적용하여 자료 처리 하였다.
핑별 오측 자료 제거 기법은 자료 처리자의 판단을 기준으 로 해저면과 오차를 보이는 오측 자료를 제거한다. 반면, CUBE 알고리즘은 자료 처리자가 그 해역의 특징에 맞게 지정 한 설정 값에 의거하여 가상의 해저면을 형성하고 이 가상의 해저면을 기준으로 일정 범위 밖의 오측자료를 일괄적으로 제거하는 기법이다. 따라서 CUBE 알고리즘은 연구 해역의 특징을 잘 파악하여 각 요소에 적절한 설정 값을 지정해 주는 게 가장 중요하며, 이러한 설정 요소들은 사용 프로그램에 따라 조금씩 차이가 있기 때문에 가상 해저면을 구현하는데 필요한 각 요소들의 설정 값을 바꾸어 가면서 처리 결과를 확인 하였다. 기본적으로 $\mathrm{CUBE}$ 알고리즘은 TPE (total propagated error)를 기반으로 자료를 처리하기 때문에 위치 (naviagation), 모션센서의 자이로 (gyro), 헤딩 (heading), 히브 (heave), 롤 (roll), 피치 (pitch) 값과 각 부가 관측 장비의 정확한 오프셋을 정확히 측정하여 각 프로그램에 적용하였다. $\mathrm{PDS} 2000$ 프로그램의 경우, CUBE 알고리즘 필터링에서 가상 의 해저면을 형성하는데 있어 cell size는 수심의 $10 \%$ 이내로 설정하고, 격자내부에 30 개 이상의 측심자료가 분포하도록 하였다. 이때 가상의 CUBE 해저면은 적용한 cell size와 $\mathrm{IHO}$ (international hydrographic organization)등급에 따라 수평 오차 한계 영향권 안에 있는 모든 수심을 적용하여 형성되었다. HIPS 프로그램 상에서 CUBE 필터링을 적용하기 위해서는 각 장비의 TPE 값을 계산하여야 하기 때문에 CARIS사에서 지정한 값을 현 탐사장비에 맞게 vessel configuration에 설정하 여 (Table 1; CARIS, 2006), CUBE 필터링을 실시하였다. HIPS 프로그램에서 가상의 CUBE 해저면을 형성하기 위해 GR (grid resoulution), EO (CUBE estimate offset parameter value), CDS (CUBE capture distance scale parameter value), CDM (CUBE capture distance minimum parameter value), HES (CUBE horizontal error scale parameter value), DM (CUBE disambiguation method) 등의 요소를 적용하였다.

\section{결과 및 고찰}

조사해역의 수심 측량 후, 수심 $40 \mathrm{~m}$ 를 기준으로 수심이 얕은 지역과 깊은 지역으로 크게 나누었으며 지형의 기복에

Table 1. Manufacturer accuracy values for total propagated error computation (CARIS, 2006)

\begin{tabular}{|c|c|c|c|c|}
\hline & Model & Manufacturer accuracy & HIPS value & Setting / Comments \\
\hline Navigation & CSI Wireless & $<1 \mathrm{~m}$ 95\% confidence & 0.51 & DGPS \\
\hline Gyro / Heading & Ixsea & $\pm 0.1^{\circ}$ RMS Secant Latitude & $0.1 \times \operatorname{Sec}$ & Gyrocompass \\
\hline Heave & Ixsea & $5 \mathrm{~cm}$ or $5 \%$ of amplitude & 0.05 & Whichever is higher \\
\hline Roll / Pitch & Ixsea & $\pm 0.01^{\circ} \mathrm{RMS}$ & 0.01 & For $\pm 90^{\circ}$ amplitude \\
\hline
\end{tabular}

Table 2. The types of sea surfaces and errors in the study area

\begin{tabular}{cll}
\hline Study area & Seafloor type & Distribution of the error data \\
\hline Area A & shallow depth, undulating surface, existence of artificial material & around the artificial material \\
Area B & shallow depth, gentle undulating surface & wide area \\
Area C & deep depth, gentle undulating surface & parallel direction with survey line \\
Area D & gradually getting shallow depth & the deep or shallow area \\
\hline
\end{tabular}


따라 완만한 지역과 급격한 변화가 보이는 지역으로 총 4 가지 로 분류하여 오측 자료를 처리하였다 (Table 2, Fig. 5). 인공구 조물 (어초)은 $\mathrm{A}$ 지역 중앙부에 분포되어 있다.

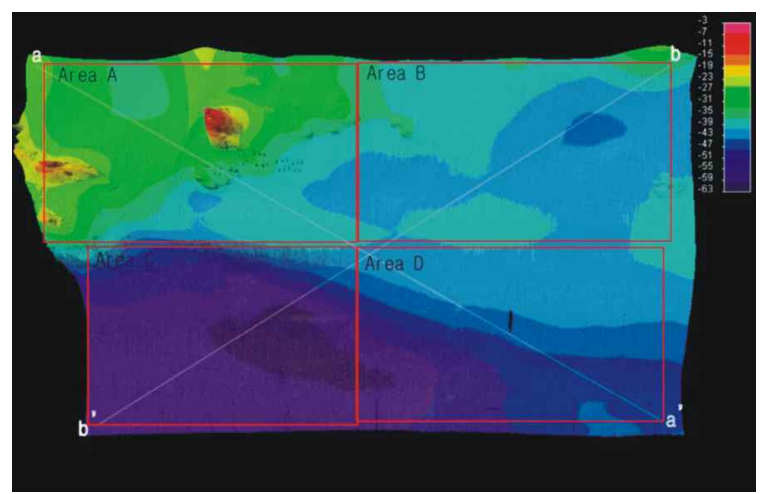

Fig. 5. Classification of sea surface types in the study area according to depth and topographic features.
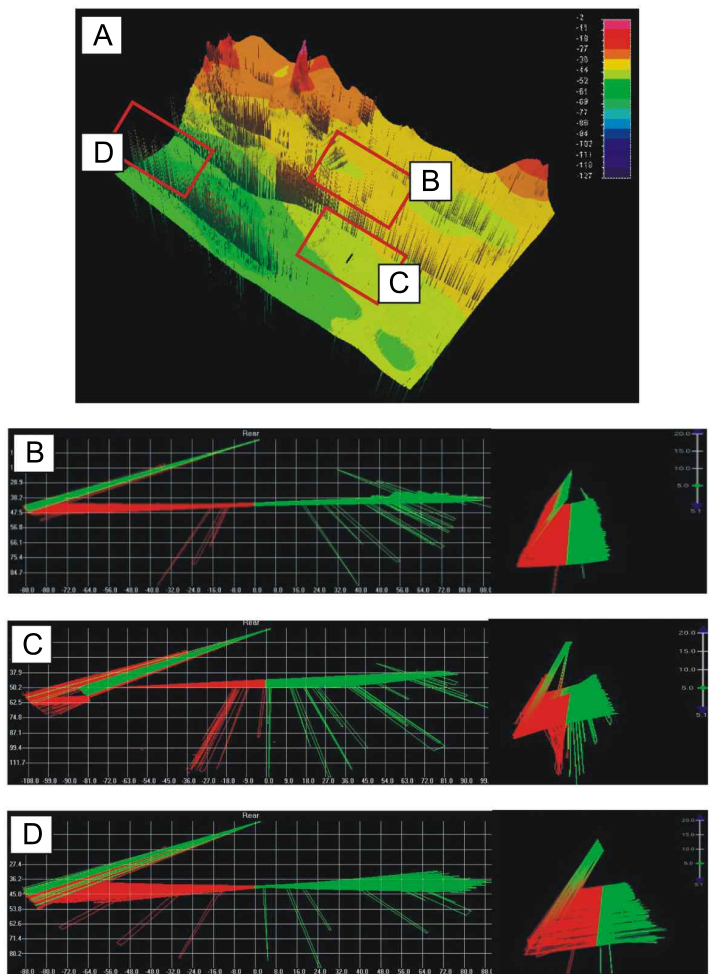

Fig. 6. Raw data in study area (A) and error data patterns $(\mathrm{B}, \mathrm{C}$, and $\mathrm{D})$. Note the wedge-shaped errors indicated in green color in the left of figures $(\mathrm{B}, \mathrm{C}$, and $\mathrm{D})$.

\section{핑별 오측 자료 제거 기법을 이용한 결과}

Fig. 6은 본 연구해역에서 획득 한 원시 수심 측량 자료와 자료 획득 시 수신 된 빔의 분포 양상을 보여준다. 연구해역 전체에서 많은 오측 자료가 나타났으며, 특히 동서 측선라인 의 외곽 빔에서 오측자료가 많이 발생하는 것을 볼 수 있다.
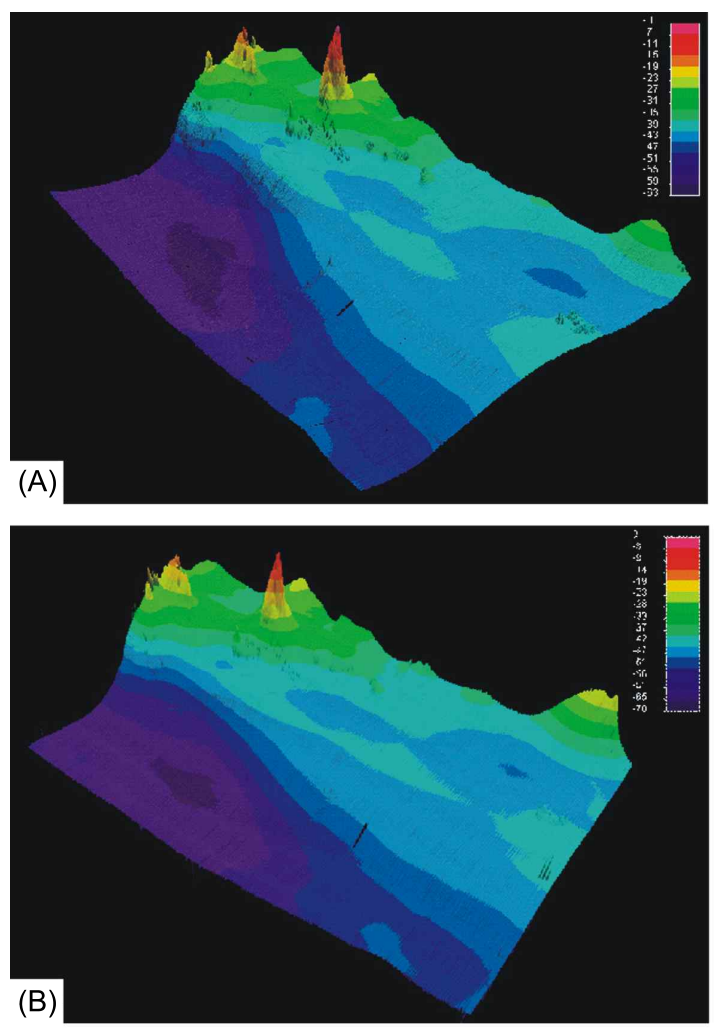

Fig. 7. The results of removal of error data by interactive editing of PDS2000 (A) and HIPS (B). Note the differences of resolution in the artifacts area between (A) and (B).

일반적으로 오측 자료는 선박의 프로펠러, 엔지의 잡음, 어류 의 움직임 및 수층 등에 의하여 빔이 해저면까지 도달하지 못하고 되돌아와 수신기에 탐지되어 나타나는 것으로 알려져 있다 (Hughes Clark, 2007). 본 연구해역에서도 이러한 원인에 의한 오측 자료가 일부 나타난다. 하지만 대부분의 오측 자료 가 선박 거동 시 좌측 해수면 가까이에서 나타나는 것을 확인 할 수 있는데 (Figs. 6B, C, and D), 이는 자료 획득 시 소나 진동자가 선체의 우측면에 설치되어 좌측 외각에 해당하는 일부 음파가 선체의 우측 선저외곽 (bottom plate)에 반사되면 서 오측 자료로 나타나는 것으로 판단된다. 연구해역에서 나 타나는 오측 자료는 우선 PDS2000과 HIPS 프로그램을 이용하 여 각각 핑별 오측 자료 제거 기법으로 자료를 처리하였다 (Fig. 7).

두 프로그램의 핑별 오측 자료 제거 기법으로 처리한 결과, 대부분의 오측 자료가 제거되고 매끄러운 해저면이 구현된 것을 확인 할 수 있다. 하지만 여전히 일부 지역에서 오측 자료가 남아있으며, 두 프로그램에서의 처리결과에서도 차이 가 나타나는 것을 확인할 수 있다 (Fig. 7). 우선 PDS2000을 이용해 핑별 오측 자료를 제거한 해저면에서는 인공구조물 인근에서 오측 자료가 일부 남아 있는 것을 확인할 수 있다 (Fig. 7A). 반면 HIPS 프로그램에서 핑별 오측 자료를 제거한 해저면은 인공구조물 주변에서 오측 자료는 없지만 인공구조 물 자체의 형태가 선명하지 않을 뿐 아니라 그 형태를 확인하 
기 어렵다 (Fig. 7B). 이는 오측 자료를 제거 할 당시, HIPS 프로그램을 이용해 먼저 자료를 처리 하게 되었는데, 이때 인공구조물의 존재를 알지 못하고 이를 오측 자료로 판단하여 상당부분 제거하였기 때문이다. 반대로 PDS2000 프로그램에 서는 인공구조물의 형태를 유지하려다 보니 상당부분의 오측 자료가 남게 된 것으로 생각된다. 이처럼 핑별 오측 자료 제거 기법은 자료처리자의 주관적 판단이 많이 개입되게 되는데, 복잡한 해저지형에서 자료 처리자가 오측 자료의 기준을 어디 에 두느냐에 따라 그 결과가 많이 달라 질 수 있음을 시사한다 (Calder and Mayer, 2001; Calder, 2003; Mallace and Gee, 2004; Calder and Wells, 2007).

$\mathrm{PDS} 2000$ 의 $\mathrm{CUBE}$ 알고리즘을 이용한 결과

4 개로 분류된 각 지역마다 측심 자료를 기반으로 측심간의 가중치를 계산하여 $\mathrm{CUBE}$ 알고리즘 필터링을 적용하였다. PDS2000에서 cell size, IHO 등급, filter factor 3가지 요소에 따라 CUBE가 실행되며, 각 요소들의 설정 값에 따라 자료 처리 결과가 다르게 나타난다. Fig. 8A는 Area A 지역에서 Table 3의 적용 설정 값 중에서 가장 좋은 해저면 이미지를 보여주는 Test 13 (cell size=2, IHO 등급 $=1$ 등급, filter factor= 15)의 처리 결과이다. Table 3의 설정 값들을 하나씩 적용하면 서 각 요소들의 영향력을 살펴보고 가장 적합한 설정 값으로 Test 13 (cell size $=2$, IHO 등급 $=1$ 등급, filter factor $=15$ )을 선택 하였다. 셀 크기는 값이 클수록 오측 자료의 제거율은 높지만 실제 해저지형의 측심 자료가 함께 제거가 되는 형상이 나타 났다. 반면 셀 크기가 작을수록 실제 해저 지형 측심 자료의
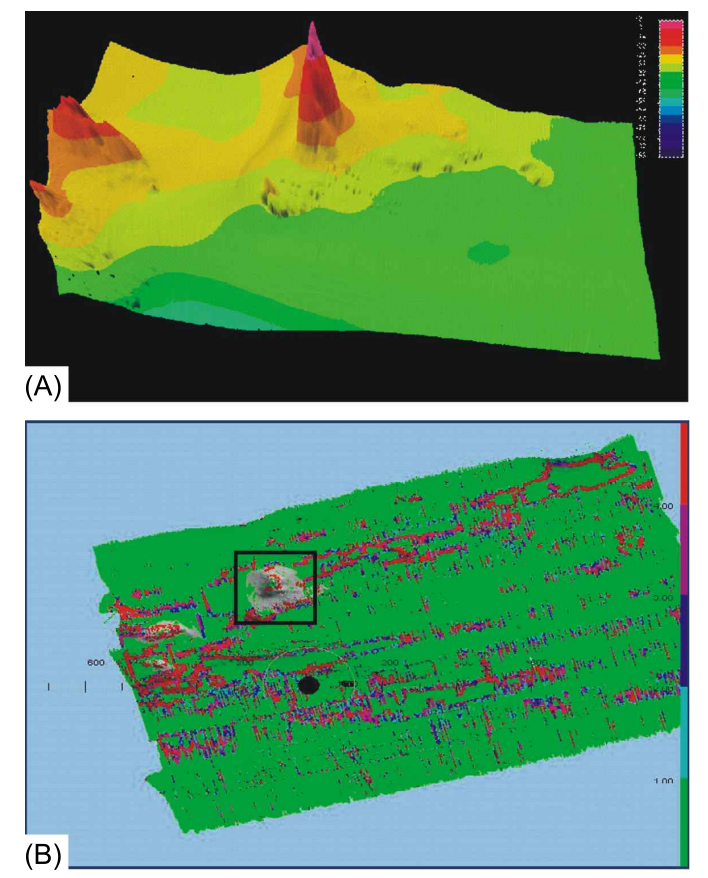

Fig. 8. (A) The result of processed surface using Test 13 in Table 3. The result shows improved topography except the artifacts area. (B) The area of artifacts without in CUBE filtering (gray color in a box).
제거 없이 연속적이면서도 매끄러운 해저면이 만들어졌다. 일반적으로 셀 크기를 줄일수록 정밀한 표현은 가능하지만, 너무 작은 셀 크기 설정은 지형의 변화가 급격한 곳에서 일부 측심 자료를 손실시키는 것으로 생각된다. IHO 등급에 따른 변화는 크지 않은 것으로 판단되며 연구해역이 정밀한 수심 자료가 요구되는 항로 및 항구 지역이 아니기 때문에 1 등급의 $\mathrm{IHO}$ 등급으로도 충분한 정밀 해저지형을 구현 할 수 있었다. 계수는 (filter factor) 값을 작게 설정할수록 오측 자료의 제거 비율이 높아지면서 실제 해저 지형에 가깝게 표현되지만 오측 자료와 함께 인공구조물의 측심 자료 역시 함께 제거가 되어 형태가 정확하게 표현되지 않는 특징이 나타났다. 따라서 본 연구에서는 Fig. $8 \mathrm{~B}$ 와 같이 가상의 해저면을 선택하는 단계에 서 인공구조물이 존재하는 지역은 구역화 하여 $\mathrm{CUBE}$ 필터링 을 실행하지 않고 핑별 오측 자료 제거 방법으로 이 구역만 자료처리 하였다. 그 결과 가장 좋은 해저면 이미지를 구현 할 수 있었다.

Table 3. Different CUBE configuration by PDS2000

\begin{tabular}{cccc}
\hline Configuration & Cell size & IHO order & Filter factor \\
\hline Test 1 & 2 & Special Order & 5 \\
Test 2 & 10 & Order 3 & 50 \\
Test 3 & 6 & Order 3 & 50 \\
Test 4 & 4 & Order 3 & 50 \\
Test 5 & 2 & Order 3 & 50 \\
Test 6 & 1 & Order 3 & 50 \\
Test 7 & 2 & Special Order & 10 \\
Test 8 & 2 & Order 1 & 10 \\
Test 9 & 2 & Order 2 & 10 \\
Test 10 & 2 & Order 3 & 10 \\
Test 11 & 2 & Order 1 & 20 \\
Test 12 & 2 & Order 1 & 10 \\
Test 13 & 2 & Order 1 & 15 \\
Test 14 & 2 & Order 1 & 1 \\
Test 15 & 2 & Order 1 & 50 \\
Test 16 & 5 & Order 1 & 30 \\
\hline
\end{tabular}

이러한 Area A 지역에서의 각 요소들의 설정 값의 특징을 이용하여 나머지 지형인 Area B, Area C, Area D에 적용하여 CUBE 알고리즘을 이용한 오측 자료 제거를 하였다 (Fig. 9). Area B는 Area A와 수심이 유사하여 셀 크기 및 계수의 변화 없이 자료처리가 가능하였다 (Table 3, Test 13; Fig. 9A). 그 외 수심이 깊고 평탄한 $\mathrm{Area} \mathrm{C}$ 에서는 계수의 값을 50 으로 설정하여 자료처리 하였으며 (Table 3, Test 15; Fig. 9B), 수심 의 변화가 큰 Area D에서는 셀 크기를 5 로 설정하고 계수 값을 30으로 지정하여 처리하였다 (Table 3, Test 16; Fig. 9C). 그 결과 모든 지역에서 오측 자료가 발견되지 않을 정도로 매끄러운 해저지형을 도시화 할 수 있었다 (Fig. 9).

HIPS의 CUBE 알고리즘 요소 및 결과

$\mathrm{HIPS}$ 의 $\mathrm{CUBE}$ 알고리즘 필터링은 $\mathrm{GR}, \mathrm{EO}, \mathrm{CDS}, \mathrm{CDM}$, $\mathrm{HES}, \mathrm{DM}$ 의 6가지 요소들을 설정 하게 되어 있어 PDS2000 보다 복잡한 구조이다. Fig. 10은 각각의 설정 값을 변화시켜 

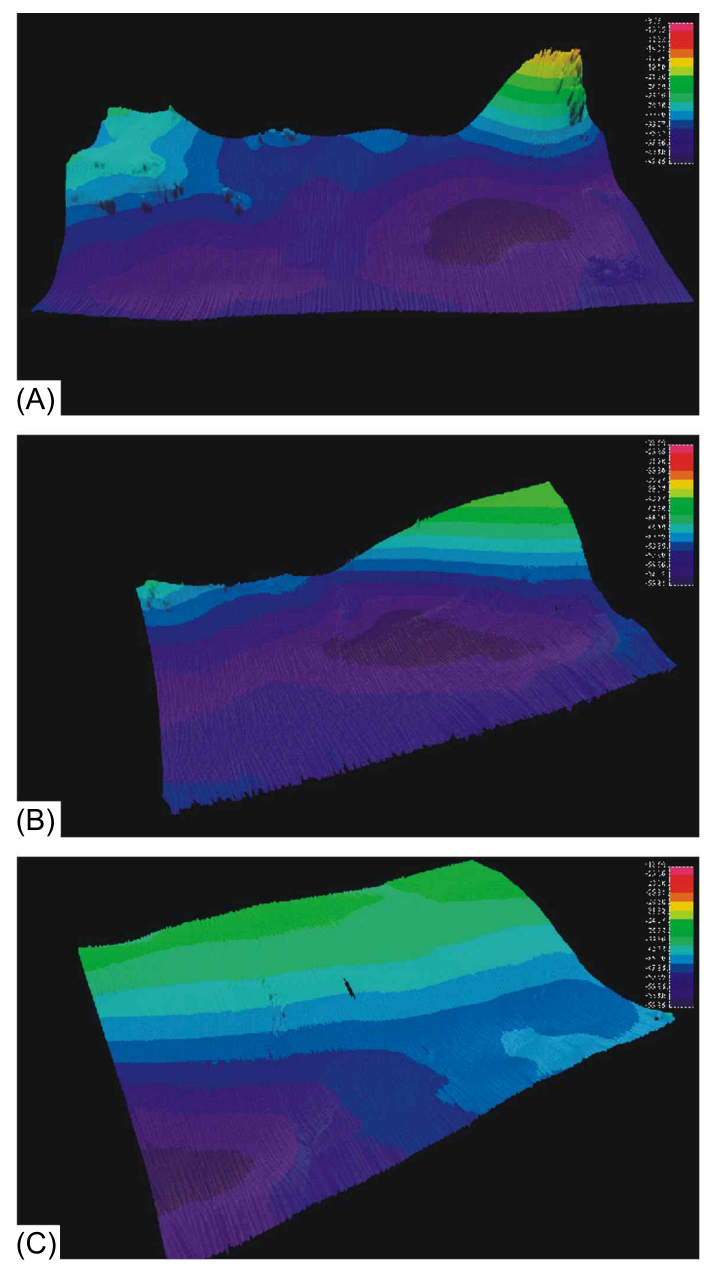

Fig. 9. The regional processed results of PDS2000 program using CUBE filtering; (A) Area B (Test 13), (B) Area C (Test 15), and (C) Area D (Test 16) indicated in Table 3, respectively.
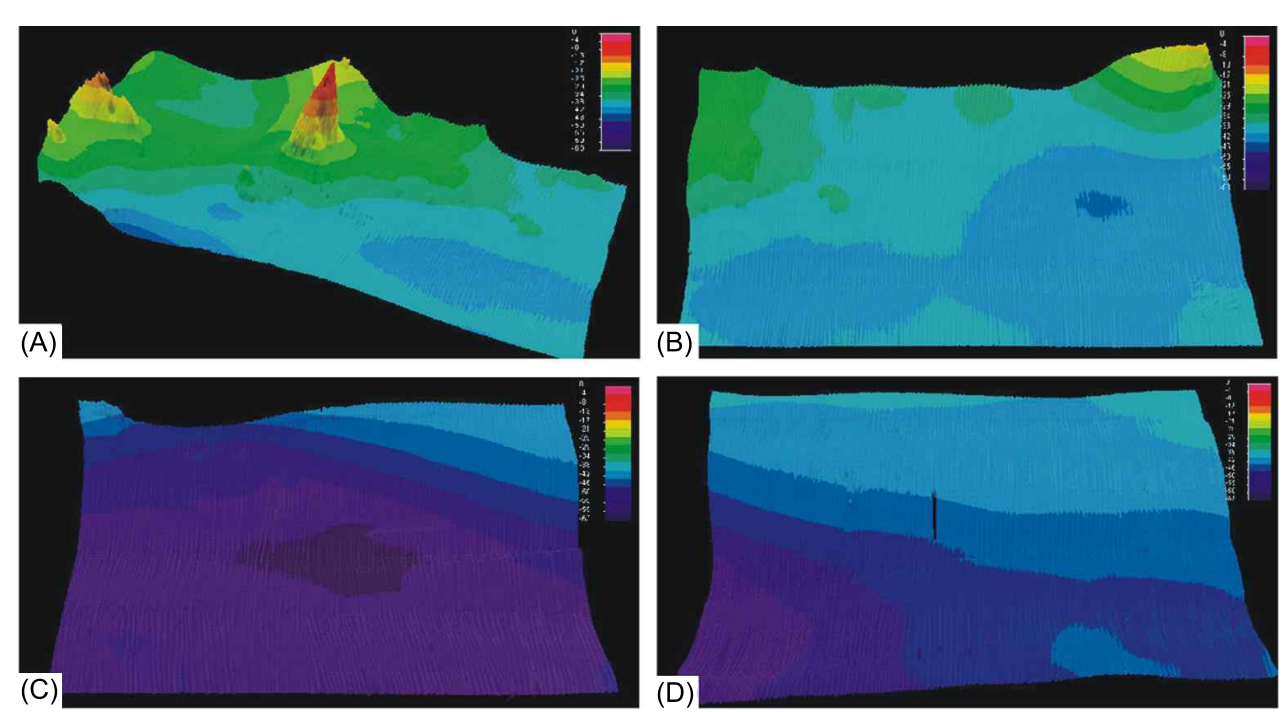
and Locale.

Fig. 10. The regional processed results of HIPS program using CUBE filtering; (A) Area A (Test 7), (B) Area B (Test 7), (C) Area C (Test 6), and (D) Area D (Test 6) indicated in Table 4, respectively.

Table 4. Different CUBE configuration in Area A by HIPS

\begin{tabular}{|c|c|c|c|c|c|c|}
\hline Configuration & GR & EO & CDS & CDM & HES & DM \\
\hline Test 1 & $\mathrm{M}$ & 4 & 5 & 0.5 & 2.95 & \\
\hline Test 2 & S & 4 & 5 & 0.5 & 2.95 & \\
\hline Test 3 & S & 4 & 5 & 0.5 & 2.95 & D \\
\hline Test 4 & $S$ & 4 & 5 & 0.5 & 2.95 & $\mathrm{DL}$ \\
\hline Test 5 & S & 4 & 5 & 0.5 & 2.95 & L \\
\hline Test 6 & $S$ & 3 & 20 & 2 & 2.95 & $\mathrm{DL}$ \\
\hline Test 7 & S & 2 & 4 & 0.4 & 0.5 & DL \\
\hline Test 8 & $S$ & 4 & 2 & 0.2 & 2.95 & $\mathrm{DL}$ \\
\hline Test 9 & S & 4 & 2 & 0.2 & 0.5 & $\mathrm{DL}$ \\
\hline Test 10 & S & 4 & 5 & 0.5 & 0.5 & $\mathrm{DL}$ \\
\hline Test 11 & S & 3 & 5 & 0.5 & 2.95 & $\mathrm{DL}$ \\
\hline Test 12 & S & 3 & 2 & 0.2 & 2.95 & DL \\
\hline Test 13 & $S$ & 3 & 2 & 0.2 & 0.5 & $\mathrm{DL}$ \\
\hline Test 14 & S & 3 & 5 & 0.5 & 0.5 & DL \\
\hline Test 15 & $S$ & 5 & 5 & 0.5 & 2.95 & $\mathrm{DL}$ \\
\hline Test 16 & S & 5 & 2 & 0.2 & 2.95 & DL \\
\hline Test 17 & S & 5 & 2 & 0.2 & 0.5 & DL \\
\hline Test 18 & S & 5 & 5 & 0.5 & 0.5 & DL \\
\hline Test 19 & $S$ & 4 & 2 & 0.2 & 3.4 & $\mathrm{DL}$ \\
\hline Test 20 & S & 3 & 30 & 3 & 3 & $\mathrm{DL}$ \\
\hline Test 21 & $S$ & 4 & 30 & 3 & 3 & $\mathrm{DL}$ \\
\hline Test 22 & $S$ & 4 & 30 & 3 & 0.5 & $\mathrm{DL}$ \\
\hline Test 23 & $S$ & 4 & 20 & 2 & 2.95 & $\mathrm{DL}$ \\
\hline Test 24 & $S$ & 4 & 5 & 0.5 & 3.4 & DL \\
\hline Test 25 & $S$ & 2 & 2 & 0.2 & 2.95 & $\mathrm{DL}$ \\
\hline
\end{tabular}

GR: Grid resolution, S: Single resolution, M: Multi resolution, EO: CUBE Estimate Offset parameter value, CDS: CUBE Capture Distance Scale parameter value, CDM: CUBE Capture Distance Minimum parameter value, HES: CUBE Horizontal error Scale parameter value, DM: CUBE Disambiguation method, D: Density, L: Locale, DL: Density 
가장 좋은 해저면 이미지를 만들어 내는 설정 조합에 의한 결과들이다. GR은 수심에 따라 해상도 값을 달리 적용했을 때 설정한 수심 경계면에서 CUBE 알고리즘 수행 문제가 발생 하여 해저면이 끓어 진 듯 한 형상으로 나타나기 때문에 (Vásquez, 2007) 해저면을 완만하게 나타내기 위하여 grid resolution을 수심의 $10 \%$ 에 해당하는 $1.5 \mathrm{~m}$ 로 값을 정하고 단 일 격자 해상도 (single grid resolution) 를 사용하였다 (Table 4). Fig. 10에 적용된 DM은 density and locale 이며, 이는 연구해 역에서 오측 빔이 밀집되어 있는 경우 density 방법만을 사용하 여 CUBE 알고리즘을 실행하였을 때 오측 자료가 거의 제거되 지 않는 효과를 가져 올 것이라 판단되었기 때문이다 (CARIS, 2006). EO는 설정 값을 작게 해줄수록 세심한 지형 변화에도 효과를 주어 수심변화가 적은 지형에서도 오측 자료를 잘 처리하지만 일부 실제 자료마저 오측 자료로 판단하여 제거하 기도 하였다. 따라서 $\mathrm{EO}$ 는 2 또는 3 이 가장 적합하였다 (Table 4, Fig. 10). $\mathrm{CDM}$ 과 $\mathrm{CDS}$ 는 똑같이 수평 반경을 제한하는 요소 이지만 $\mathrm{CDM}$ 은 $\mathrm{CDS}$ 의 $10 \%$ 에 해당하는 최소값을 의미하며 그 값의 변화에는 큰 영향을 끼치지 않는 것으로 사료되어 $\mathrm{CDM}$ 은 $\mathrm{CDS}$ 의 $10 \%$ 값을 적용하였다 (CARIS, 2006). $\mathrm{CDS}$ 와 $\mathrm{CDM}$ 의 값이 클수록 해저지형의 수심 차가 적은 부분까지도 오측 자료의 제거가 원할 하게 이루어짐을 알 수 있었으며, 지역에 따라 설정 값을 조금씩 변화시켜 주어야 가장 좋은 이미지를 얻을 수 있다.

이러한 각 요소의 특징들을 바탕으로, 수심이 얕고 인공구 조물이 존재하는 구역인 Area $\mathrm{A}$ 와 수심이 얕은 곳인 Area $\mathrm{B}$ 지역에서는 $\mathrm{EO}=2, \mathrm{CDS}=4, \mathrm{CDM}=0.4, \mathrm{HES}=0.5$ 로 값을 설 정하였고 (Table 4, Test 7; Figs. $10 \mathrm{~A}$ and 10B), 수심이 깊고 인공구조물이 거의 없는 Area $\mathrm{C}$ 와 Area $\mathrm{D}$ 지역에서는 $\mathrm{EO}=3$, $\mathrm{CDS}=20, \mathrm{CDM}=2, \mathrm{HES}=2.95$ 를 적용하였다 (Table 4, Test 6; Figs. $10 \mathrm{C}, 10 \mathrm{D})$. 그 결과 수심이 얕은 지역인 Area A와 Area $\mathrm{B}$ 지역에서는 핑별 오측 자료 제거 방법을 이용한 자료 처리 결과와 유사한 결과를 보였으며, 수심이 깊은 지역인 Area $\mathrm{C}$ 와 Area $\mathrm{D}$ 는 오측 자료의 일부가 완전히 처리 되지 못한 부분은 있지만 전체적으로 좋은 해저지형을 구현하였다.

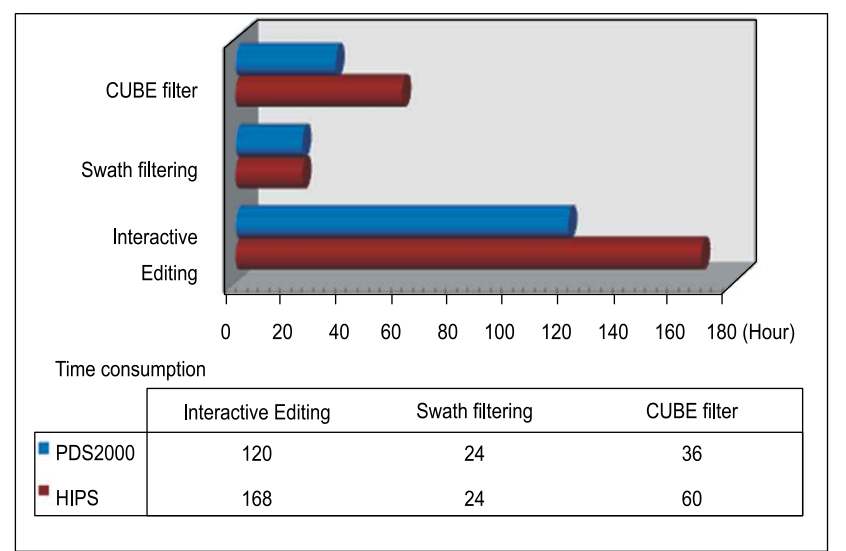

Fig. 11. Comparison of time consumption of the filtering method with PDS2000 and HIPS postprocessing programs.
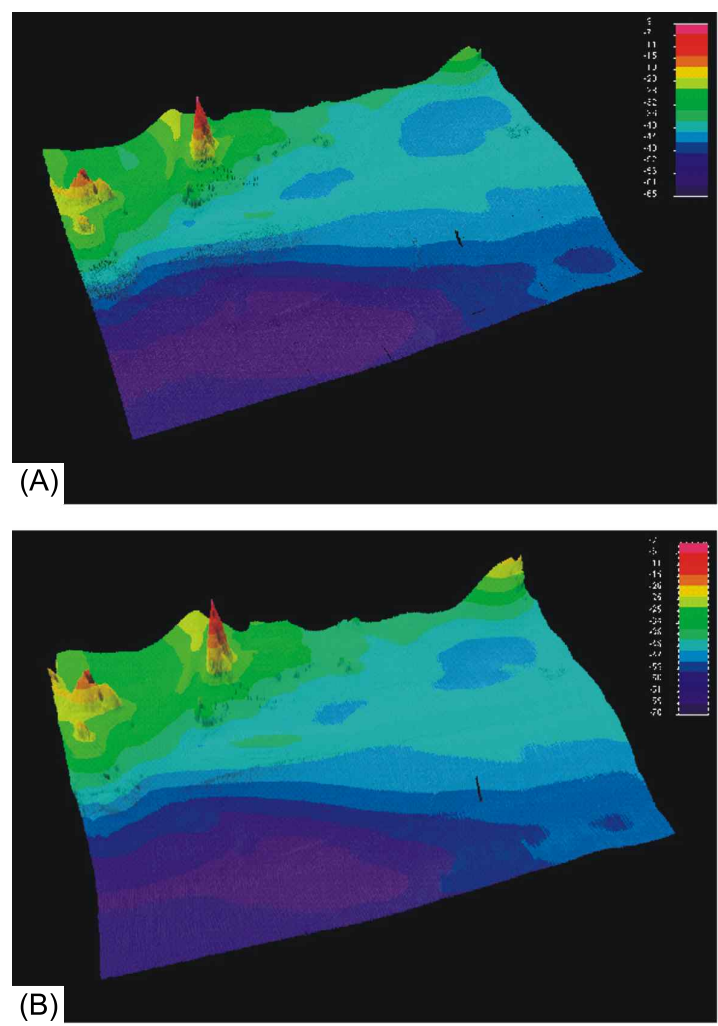

Fig. 12. The results of surface using CUBE filter by PDS2000 (A) and HIPS (B). Note the more detailed but slightly rough image (A) processed by PDS2000.

핑별 오측 자료 제거 방법과 $\mathrm{CUBE}$ 알고리즘을 이용 한 방법의 비교

본 연구지역에서 획득한 수심자료를 PDS2000과 HIPS 프로 그램을 이용해 핑별 오측 자료 제거 방법으로 처리한 결과 Fig. 7과 같은 해저면으로 구현하는데 각 프로그램 별로 120시 간과 168 시간이 소요되었다 (Fig. 11). 반면 CUBE 필터링을 이용해 Fig. 12와 같은 결과를 제시하기까지는 각 프로그램 별로 36 시간과 60 시간의 자료처리 시간이 소모되었다. 이는 자료처리자의 숙련도나 프로그램 사용에 대한 지식의 정도에 따라 차이가 있겠지만 기본적으로 $\mathrm{CUBE}$ 필터링의 사용이 핑별 오측 자료 제거 방법에 비해 자료처리에 할애되는 시간 을 많이 절약 할 수 있음을 시사한다. 제거 기법에 상관없이 HIPS 프로그램을 통한 자료처리 시간이 PDS2000 프로그램을 이용하는 것보다 더 많은 시간이 소요 된 것은 자료처리자가 HIPS 프로그램 사용에 대한 숙련도가 좀 더 떨어졌기 때문이 다. 또한 $\mathrm{HIPS}$ 의 더 많은 $\mathrm{CUBE}$ 필터링 설정 값 역시 자료처리 시간을 지연 시켰다.

핑별 오측 자료 제거 방법과 CUBE 필터링을 이용한 방법 모두 사용된 자료처리 프로그램에 (PDS2000 또는 HIPS) 따라 해저면 구현 결과에서 약간의 차이가 나타났다 (Figs. 7, 12). 전반적으로 PDS2000 프로그램을 이용해 구현한 해저면은 인 공구조물과 같은 작은 수직 변화를 보이는 수심까지도 자세하 
게 잘 표현하였으며, HIPS 프로그램은 전체적으로 부드러우 면서 연속적인 해저면을 구현하였다. 이는 핑별 오측 자료 제거 방법을 사용 시에는 자료 처리자의 주관적 판단이 개입 되면서 인공구조물과 같은 요인에 대한 기준을 달리 했기 때문에 전체적인 자료의 형태가 달라진 것으로 판단된다. $\mathrm{CUBE}$ 알고리즘 필터링을 이용한 결과의 차이는 비록 각 상용 프로그램이 같은 $\mathrm{CUBE}$ 필터링을 사용하지만 적용되는 요소의 종류와 효과가 프로그램마다 차이가 있기 때문으로 생각된다. 비록 이와 같은 자료처리 프로그램에 따른 결과의 차이는 있지 만 $\mathrm{CUBE}$ 필터링은 일정한 설정 값에서는 자료처리자의 주관적 판단에 따른 변화를 배제한 결과를 얻을 수 있음을 알 수 있다. 따라서 연구해역의 특성 및 오측 자료의 분포 경향을 충분히 파악하고 $\mathrm{CUBE}$ 알고리즘 필터링의 각 설정 값 적용에 대한 숙련도만 확보한다면 CUBE 알고리즘 필터링을 통해 수심 자료 의 처리에 있어 많은 시간을 절약함과 함께 일관성 있는 양질의 해저면을 구현 할 수 있을 것으로 판단된다.

$$
\text { 사 사 }
$$

본 연구는 국토해양부의 국가 R\&D 사업인 “동북아해 퇴적 물 기원연구 및 모니터링” (과제번호: PM546-11, 주관연구기 관: 한국해양연구원)에 의해 수행 되었습니다. 탄성파 자료획 득에 도움을 준 지마텍(주) 직원들께 감사드립니다.

\section{참고문헌}

Alan H. Swath Bathymetry ROG. http://www.searchmesh.net on 2007.

Carder B. 2003. Automatic Statistical Processing of Multibeam Echosounder Data. International Hydrographic Review 4, 2-3.

Calder B and Wells D. 2007. CUBE user's manual. Unpublished report of the Center for Coastal and Ocean Mapping Group \& Joint Hydrography Center, University of New Hamsphire, Durham, NH, U.S.A.

Calder B and Mayer L. 2001. Robust Automatic Multi beam Bathymetric Processing. In: Proceeding of the 2001 Hydrographic Conference, Norfolk, VA. U.S.A. 22-24 May, ed. Center for Costal and Ocean Mapping Group \& Joint Hydrography center, University of New Hampshire, Durham, NH, U.S.A., 2-10.

CARIS. 2006. Convert in raw data and CUBE processing; Standard operating procedure, March - April.

CARIS. 2007. Standard Operating procedures for KONGSBERG MARITINE MBES DATA, January.

Christian de Moustier. 2008. Sound refraction in the water column lecture 13. In: Coastal Multibeam Sonar Training Course Notes, ed. Ocean Mapping Group, Department of Geodesy and Geomatics Engineering, University of New Brunswick, Canada.
Godin A. 1996. The Calibration of Shallow Water Multibeam Echo-sounding Systems. In: Proceedings Of the Canadian Hydrographic Conference, ed. Halifax, Nova Scotia, 25-31.

Hammack JA, Fabre DH, Hughes Clarke JE and Reed B. 1998. Hydrographic multibeam processing system (HMPS) swath alignment tool: Proceedings Canadian Hydrographic Conference 1998. Victoria, 157-167.

Hare R. 2001. Error budget analysis for US naval oceanographic office hydrographic survey systems. Prepared at the University of southern Mississippi, hydrographic science research center (HSRC) for the Naval Oceanographic Office.

Herlihy DR, Hillard BF, and Rulon TD. 1989. National Oceanic and Atmospheric Administration Sea Beam Patch test manual: Ocean Mapping Section. Office of Charting and Geodetic Services, NOS, 34

Hillard BF, and Rulon TD. 1989. National Oceanic and Atmospheric Administration HydroChart II system Patch Test Manual: Ocean Mapping Section. Office of Charting and Geodetic Service, NOS, 35

Hughes Clark JE. 1997. Field Calibration: the Patch Test and the Reference Surface lecture 18. In: 1997 Coastal Multibeam Sonar Training Course Notes, ed. Ocean Mapping Group, Department of Geodesy and Geomatics Engineering, University of New Brunswick, Canada.

Hughes Clark JE. 2007. Field Calibration: the Patch Test and sensor to ship reference frame alignment lecture 24. In: 2007 Coastal Multibeam Sonar Training Course Notes, ed. Ocean Mapping Group, Department of Geodesy and Geomatics Engineering, University of New Brunswick, Canada.

Jung YJ. 2008. Observation and Characteristics of Tides and Tidal currents in the South Sea of Korea. Ph.D. Thesis, Pukyoung National University, Busan, Korea.

KHOA. 2008. Numerical Tidal Current Diagram of Namhae.

Kim YS. 2005. Research on the Methods of Improving Coastal Survey Accuracy with Single-Beam and Multi-Beam Echo Sounder. Ph.D. Thesis, Pukyoung National University, Busan, Korea.

Korea Institute of Energy Resources. 1986. Marine Geological study of the continental shelf between Namhae-do and Geoje-do, southern coast, Korea. KIER Report KR-86-20, 1-64.

Korea Institute of Energy Resources. 1987. Marine Geological study on the continental shelf between Geoje and Busan, southern coast, Korea. KIER Report 
KR-86-2-20, 1-64.

Land information New Zealand. 2000. Hydrographic MBES survey standards.

Mallace D, and Gee L. 2004. Multibeam Processing "The end to manual editing?". In: Proceeding of the Canadian Hydrographic Conference Ottawa, ON, CANADA. 25-27 May, ed. Center for Costal and Ocean Mapping Group and Joint Hydrography center, University of New Hampshire, Durham, NH, U.S.A., 3-8.

Min GH. 1994. Seismic stratigraphy and depositional history of pliocene-holocene deposits in the southeastern shelf, Korea Peninsula. Ph.D. Thesis, Seoul National University, Seoul, Korea.

NOAA. 2004. Hydrographic surveys multibeam echosounder calibration report.

Orange DL, Angell MM and Lapp D. 1999. Using Seafloor Mapping (Bathymetry and Backscatter) and High Resolution Sub-Bottom Profiling for both Exploration and Production; Detecting Seeps, Mapping Geohazards, and Managing Data Overload with GIS.
30thAnnual Offshore Technology Conference, Houston, Texas, U.S.A., 3-6.

Park YS. 2004. Study on Error Analysis and Data Processing for Multi-Beam Swath Sonar System. Ph.D. Thesis, Inha University, Incheon, Korea.

Smith FW. 1991. Estimating array misalignment errors in the Sea Beam sonar system: NOAA SBIR phase II final report. Contrack 50-DKNA-9-00144.

Susan S and Wells D. 2000. Analysis of Multibeam Crosschecks Using Automated Methods. U.S. Hydro 2000 Conference paper, Biloxi, Mississippi.

Wells D, Mayer LA and Hughes Clarke JE. 1991. "Ocean Mapping: from Where? To What?". CISM Journal of ACSGC 45(4). 505-518.

2010년 11월 30일 접수

2011년 3월 14일 수정

2011년 6월 8일 수리 